\title{
Correction to: Adverse drug reaction reporting in Canada: consumer versus physician reports
}

\author{
Rania Al Dweik $^{1}$ ( ) Dafna Kohen ${ }^{2} \cdot$ Dawn Stacey $^{3} \cdot$ Sanni Yaya ${ }^{4}$
}

Published online: 14 August 2020

C) Springer Nature Switzerland AG 2020

\section{Correction to: Drugs \& Therapy Perspectives https://doi.org/10.1007/s40267-020-00762-6}

While typesetting the article the word "physician" has been inadvertently deleted.

The correct title has been given below:

Adverse drug reaction reporting in Canada: consumer versus physician reports

The original article has been updated.

The original article can be found online at https://doi.org/10.1007/ s40267-020-00762-6.

Rania Al Dweik

raldw034@gmail.com

Dafna Kohen

Dafna.Kohen@statcan.gc.ca

Dawn Stacey

dstacey@uottawa.ca

Sanni Yaya

sanni.yaya@uOttawa.ca

1 Faculty of Health Science, Public Health Department, Abu Dhabi University, Abu Dhabi, United Arab Emirates

2 Health Analysis Division, Statistics Canada, Ottawa, Canada

3 Faculty of Health Sciences, Ottawa Hospital Research Institute, Clinical Epidemiology Program, School of Nursing, University of Ottawa, Ottawa, Canada

4 School of International Development and Global Studies, Faculty of Social Sciences, University of Ottawa, Ottawa, Canada 